OPEN ACCESS

Edited by: Cheng Zhong,

Tianjin University, China

Reviewed by:

Tamara Posati,

National Research Council (CNR), Italy

Bin Mu,

Lanzhou Institute of Chemical Physics

(CAS), China

*Correspondence:

Yong-Ho Choa

choa15@hanyang.ac.kr

Specialty section: This article was submitted to

Electrochemistry,

a section of the journal

Frontiers in Chemistry

Received: 11 November 2021

Accepted: 12 January 2022

Published: 07 February 2022

Citation:

Park JY, Yoo SB, Cho H-B, Lee H-S and Choa Y-H (2022) CaFe-Based

Layered Double Oxides With Superior

Iron Alloy Corrosion Inhibition

Behaviors in Aggressive

Seawater Environment.

Front. Chem. 10:813008.

doi: $10.3389 /$ fchem.2022.813008

\section{CaFe-Based Layered Double Oxides With Superior Iron Alloy Corrosion Inhibition Behaviors in Aggressive Seawater Environment}

\author{
Ji Young Park ${ }^{1}$, Su Been Yoo $^{2}$, Hong-Baek Cho ${ }^{1}$, Han-Seung Lee ${ }^{3}$ and Yong-Ho Choa ${ }^{1 *}$ \\ ${ }^{1}$ Department of Material Science and Chemical Engineering, Hanyang University, Ansan, South Korea, ${ }^{2}$ Department of Industrial \\ $R \& D$ Center, Park Systems Corporation, Suwon-si, South Korea, ${ }^{3}$ Department of Architectural Engineering, Hanyang University, \\ Ansan, South Korea
}

Reinforced concrete is among the most multifaceted materials used in the construction field. Maintaining the resistance of reinforced concrete to weathering, abrasion, and chemical attack, particularly in aggressive natural conditions such as seawater environments, is challenging. The main factor in the degradation of reinforcedconcrete durability is chloride penetration, which accelerates iron alloy corrosion and facilitates structural degradation. In this study, calcium-iron-based layered double hydroxides (CaFe-LDHs) were fabricated at room temperature, followed by structural modulation, and their effectiveness in mitigating iron alloy corrosion due to chloride ions (in $3.5 \mathrm{wt} \%$ of $\mathrm{NaCl}$ ) was investigated. The synthesized $\mathrm{CaFe}-\mathrm{LDH}$ with phase transfer notably improved the $\mathrm{Cl}^{-}$removal capacity $\left(Q_{\max }\right)$ to $881.83 \mathrm{mg} / \mathrm{g}$, which is more than three times that reported based on previous studies. The novelty of this research lies in the sophisticated structural and phase transformations of the assynthesized CaFe-LDHs, determination of crucial factors for chloride ion removal, and suggestion of calcium-iron-based layered double oxide (CaFe-LDO)-based chloride ion removal mechanisms considering chemical and ion-exchange reactions. Moreover, when the phase-transformed LDHs, C-700 LDOs, were applied to inhibit iron alloy corrosion, a noticeable inhibition efficiency of $98.87 \%$ was obtained, which was an 11 fold improvement compared to the case of iron alloys without LDOs. We believe this work can provide new insights into the design of CaFe-LDOs for the enhancement of the lifespan of reinforced concrete structures.

Keywords: layered double hydroxide, cafe, corrosion, chloride, iron alloy

\section{HIGHLIGHTS}

- Structural transformation of CaFe-based LDOs in crystallinity and morphology

- Novel reconstruction mechanism of structure-modulated CaFe-LDOs

- Cl- removal capacity of C-700 LDOs, higher than previous reports.

- Inhibition efficiency of $98.87 \%$ was obtained comparing with iron alloys without LDOs.

- Potential in the construction industries to enhance the durability of buildings. 


\section{INTRODUCTION}

Corrosion damage to reinforcement and prestressed steel has been identified as the primary cause of a significant number of structural failures over the past centuries. It also entails a significant cost in terms of the repair, monitoring, and replacement of structures (Berrocal et al., 2016). Reinforced concrete structures are continually exposed to destructive elements that decrease their durability and lifespan. In general, concrete has high alkalinity $(\mathrm{pH}$ $>13$ ) and causes iron alloys to develop a passivation layer to prevent corrosion (Ke et al., 2017). The corrosion of reinforcement steel in concrete can only be initiated when the passivation layer is destroyed by anions, particularly chloride ions $\left(\mathrm{Cl}^{-}\right)$. The penetration of chloride into reinforced concrete is a significant threat, specifically for structures near marine environments that are exposed to high concentrations of salts. Such a scenario allows chloride ions to easily penetrate concrete structures through capillary adsorption, hydrostatic pressure, or diffusion into the iron alloys (Pradhan and Bhattacharjee, 2011; Muthulingam and Rao, 2015). Poor concrete quality or insufficient covering of concrete is deleterious to the durability of iron alloys and can lead to substantial economic losses and serious safety disasters (Bassuoni and Nehdi, 2008; Chen et al., 2016). Therefore, the selective and prompt removal of anions that cause deterioration immediately upon their penetration is desirable to maintain the durability and lifespan of concrete structures.

Layered double hydroxides (LDHs), also known as anionic clays, capture anions in aqueous solutions. The structure of LDHs is similar to the regular hexagonal structure of brucite $\left[\mathrm{M}(\mathrm{OH})_{2}\right]$, and their general chemical formula is $\left[\mathrm{M}_{1-\mathrm{x}}^{2+} \mathrm{M}_{\mathrm{x}}^{3+}(\mathrm{OH})_{2}\right]^{\mathrm{x}+}\left[\mathrm{A}_{\mathrm{x} / \mathrm{n}}^{\mathrm{n}}\right]$ ${ }^{\mathrm{x}-} \cdot \mathrm{yH}_{2} \mathrm{O}$, where $\mathrm{M}^{2+}$ (e.g., $\mathrm{Ca}, \mathrm{Mg}, \mathrm{Zn}, \mathrm{Co}, \mathrm{Ni}, \mathrm{Cu}$ ) and $\mathrm{M}^{3+}$ (e.g., $\mathrm{Fe}, \mathrm{Al}, \mathrm{Cr}$ ) are divalent and trivalent metal cations, respectively, and $\mathrm{An}$-is an n-valent anion. Owing to the substitution of $\mathrm{M}^{2+}$ with $\mathrm{M}^{3+}$ in the brucite-like metallic hydroxide $\mathrm{M}(\mathrm{OH})_{2}$, the layered structures have positive charges that are balanced by interlayer anions $\left(\mathrm{An}^{-}\right.$) (Yang et al., 2013; Mishra et al., 2018; Zuo et al., 2019). A unique property of LDHs is that their original structure can be obtained upon rehydration after calcination treatment (Erickson et al., 2005; Santos R. M. M. et al., 2017; Ivánová et al., 2018). In addition, it is well known that various anions can be selectively exchanged without altering the original structure, a feature referred to as the memory effect ( $\mathrm{Lv}$ et al., 2015). Other advantageous features of LDHs, including their high specific surface area, non-toxicity, and low cost, expand their utilization in the fields of hazardous material adsorption, catalysis, biomedicine, and agriculture (Evans and Duan, 2006; Benício et al., 2015; Lv et al., 2015).

Among the published reports on chloride adsorption with LDHs, a maximum removal capacity of $257 \mathrm{mg} / \mathrm{g}$ was reported by Yoon et al. (2014), who compared the adsorption capabilities of various LDHs with different metal hydroxide layers. CaFe-LDHs also show high potential for removing condensed phosphate ( $\mathrm{Wu}$ et al., 2012). However, the few existing studies are insufficient to understand the adsorption mechanism of CaFe-LDHs, and studies on the anion adsorption capacity are limited.

In this paper, we report the synthesis of structure-modulated calcium-iron-based layered double oxides (CaFe-LDOs) and their outstanding performance in terms of both a high chloride ion removal capacity and iron alloy corrosion protection. To evaluate the effectiveness of CaFe-LDOs in enhancing the durability of concrete, the chloride removal performance and mitigation of iron alloy corrosion by CaFe-LDOs were examined using an aqueous solution of $3.5 \mathrm{wt} \% \mathrm{NaCl}$, which corresponds to the concentration of chloride in seawater. In addition, the mechanisms of chloride ion exchange and corrosion protection were investigated.

\section{EXPERIMENTAL}

\section{Materials and Reagents}

$\mathrm{CaFe}-\mathrm{LDH}$ powders were prepared using calcium nitrate tetrahydrate $\left(\mathrm{Ca}\left(\mathrm{NO}_{3}\right)_{2} \cdot 4 \mathrm{H}_{2} \mathrm{O}, 99 \%\right)$, iron nitrate nonahydrate $\left(\mathrm{Fe}\left(\mathrm{NO}_{3}\right)_{3} \cdot 9 \mathrm{H}_{2} \mathrm{O}, 98 \%\right)$, sodium hydroxide $(\mathrm{NaOH}, 99 \%)$, and sodium chloride $(\mathrm{NaCl}, 99.5 \%)$, all of which were purchased from Sigma-Aldrich, Inc. and Daejung, Inc. without further purification. Distilled deionized water was used to prepare the standard aqueous ionic solutions.

\section{Synthesis of CaFe-LDHs}

The CaFe-LDHs (pristine LDHs) were prepared via a one-step co-precipitation method (Wu et al., 2012; Gupta et al., 2020; Kong et al., 2021; Romero Ortiz et al., 2021). In particular, the optimized conditions for $\mathrm{CaFe}-\mathrm{LDH}$ synthesis were determined by varying the $\mathrm{Ca}^{2+}: \mathrm{Fe}^{3+}$ molar ratio in the precursor solutions. First, an aqueous $3 \mathrm{M} \mathrm{NaOH}$ solution $(300 \mathrm{ml})$ was rapidly injected at a rate of $300 \mathrm{ml} / \mathrm{min}$ into a second solution $(300 \mathrm{ml})$ containing $66.7-80.0 \mathrm{mmol}$ of $\mathrm{Ca}\left(\mathrm{NO}_{3}\right)_{2} \cdot 4 \mathrm{H}_{2} \mathrm{O}$ and $33.3-20.0 \mathrm{mmol}$ of $\mathrm{Fe}\left(\mathrm{NO}_{3}\right)_{3} \cdot 9 \mathrm{H}_{2} \mathrm{O}$ at room temperature for $1 \mathrm{~min}$ to induce supersaturation. This was followed by the aging of the solution for $18 \mathrm{~h}$. The concentration of each salt was balanced according to the $\mathrm{Ca}^{2+}$ : $\mathrm{Fe}^{3+}$ molar ratio, which ranged from $2: 1$ to $4: 1$. During this process, the $\mathrm{pH}$ was controlled from 12 to 14 , and all reactions were performed at room temperature. Upon completion of the reaction, the as-formed precipitates were filtered $(200 \mathrm{~nm})$, and the synthesized CaFe-LDHs were washed with excess quantities of ethanol to remove any undesirable nitrate salt residues. The obtained crystals were stored at room temperature in a desiccator to prevent contact with moisture and carbon dioxide in the air.

\section{Structural Transformation of the CaFe-LDOs}

Structural transformations were induced in the as-prepared $\mathrm{CaFe}-\mathrm{LDH}$ s by thermal treatment. The specimens were heattreated in a furnace at $400^{\circ} \mathrm{C}(\mathrm{C}-400 \mathrm{LDOs})$ and $700^{\circ} \mathrm{C}(\mathrm{C}-700$ LDOs) for $3 \mathrm{~h}$ in air at a heating rate of $10^{\circ} \mathrm{C} / \mathrm{min}$.

\section{Removal Test of Chloride Ion in Aqueous Solution}

A chloride solution was prepared by dissolving $\mathrm{NaCl}$ in deionized water. The initial concentration of the chloride ions was $200 \mathrm{ppm}$. 
Chloride removal was conducted in $200 \mathrm{ml}$ of the aqueous ionic solution after adding $1.89 \mathrm{~g}$ of LDHs and LDO under magnetic stirring at $250 \mathrm{rpm}$.

\section{Corrosion Protection Test of Iron Alloys}

The type of steel used in the corrosion experiments was SS400 with a chemical composition (in wt\%) of $0.27 \mathrm{C}, 0.90 \mathrm{Mn}, 0.20$ $\mathrm{Cu}, 0.05 \mathrm{~S}, 0.04 \mathrm{Si}$, and $0.04 \mathrm{P}$ (Fe balance). Iron alloys (1.5 mm) were first sanded and then washed with ethanol. Iron alloy specimens for the corrosion tests were prepared using a simple microstopper coating. The surface on one side of the iron alloys was exposed to perform the corrosion experiment $(1 \mathrm{~cm} \times 1 \mathrm{~cm})$, and the remaining area was sealed with a microstopper. An electrolyte solution of $3.5 \mathrm{wt} \% \mathrm{NaCl}$, which corresponds to the typical concentration of $\mathrm{NaCl}$ in seawater, was prepared. Solution-based chloride adsorption with LDHs and LDOs (pristine LDHs, C-400 LDOs, and C-700 LDOs) and without LDHs and LDOs (bare iron alloys) was monitored. The reaction was initiated by adding $1 \mathrm{~g}$ of $\mathrm{CaFe}-\mathrm{LDH}$ and LDO powder to $250 \mathrm{ml}$ of the corrosion solution. A saturated calomel electrode (SCE) and platinum electrode (PE) were employed as the reference and auxiliary electrodes, respectively.

\section{Characterization}

The solution $\mathrm{pH}$ was measured using a FE20 pH meter (Mettler Toledo, United States) equipped with a glass electrode (LE438, Mettler Toledo, United States). Thermogravimetric (TGA) measurements were performed using a Shimadzu TGA-50 thermogravimetric analyzer. The ion concentrations in the liquids after ion exchange were determined by ion chromatography (METROSEP A SUPP 5-250) at a flow rate of $0.7 \mathrm{ml} / \mathrm{min}$ with an eluent mixture of $3.2 \mathrm{mM} \mathrm{Na}_{2} \mathrm{CO}_{3} / 1.0 \mathrm{mM}$ $\mathrm{NaHCO}_{3}$. Solid samples were characterized by Fourier transform infrared spectroscopy (FT-IR, Thermo Scientific 380 FT-IR) in the range of 4,000 to $500 \mathrm{~cm}^{-1}$ with a resolution of $4 \mathrm{~cm}^{-1}$; analysis was conducted on a $32 \mathrm{~mm}$ disc. X-ray diffraction (XRD) patterns of the solids were acquired using a D/max2200 diffractometer (Rigaku Co., Japan), operating at $40 \mathrm{kV}$ and $100 \mathrm{~mA}$, with $\mathrm{Cu} \mathrm{Ka}$ radiation $(\lambda=0.1541 \mathrm{~nm})$ in the range of $2 \theta=10-80^{\circ}$ at a scan rate of $4^{\circ} / \mathrm{min}$. The morphology was characterized using a scanning electron microscope (SEM, S4800, Hitachi Ltd. Japan) equipped with an energy-dispersive $\mathrm{X}$-ray spectroscopy (EDX) detector. The morphology and size of the as-obtained samples were observed by transmission electron microscopy (TEM, JEM-2100F, JEOL, Japan) at an accelerating voltage of $200 \mathrm{kV}$. For corrosion testing, the anti-corrosive properties and electrical conductivity of the iron alloys were determined by electrochemical measurements, including potentiodynamic polarization (PDP) and electrochemical impedance spectroscopy (EIS) measurements. The EIS measurements were performed by applying a sinusoidal potential perturbation of $10 \mathrm{mV}$ over a frequency range of $100 \mathrm{kHz}$ to $100 \mathrm{MHz}$. The obtained EIS spectra were analyzed with an equivalent circuit using the Zman software. All electrochemical measurements were performed under quiescent conditions. No attempt was made to aerate or deaerate the test solutions.

\section{RESULTS AND DISCUSSION Characterization of the Synthesized CaFe-LDHs}

CaFe-LDHs with nitrate $\left(\mathrm{NO}_{3}^{-}\right)$anions intercalated in the interlayer region were synthesized by varying the $\mathrm{pH}$ (from 12 to 14 ) and $\mathrm{Ca}^{2+}: \mathrm{Fe}^{3+}$ molar ratio (from $2: 1$ to $4: 1$ ). XRD patterns of the as-synthesized LDHs are displayed in Supplementary Figure S1. The LDHs prepared at a $2: 1 \mathrm{M}$ ratio of $\mathrm{Ca}^{2+}: \mathrm{Fe}^{3+}$ resulted in $\mathrm{CaFe}-\mathrm{LDH}$ with a crystal structure corresponding to hexagonal $\mathrm{Ca}_{2} \mathrm{Fe}(\mathrm{OH})_{6}\left(\mathrm{NO}_{3}\right) \cdot 2 \mathrm{H}_{2} \mathrm{O}$ (JCPDS No. 48-65), as shown in Supplementary Figure S1A. Such a structure is intercalated with $\mathrm{NO}_{3}{ }^{-}$anions and crystalline water, and the diffraction peaks are located at $2 \theta$ values of approximately $10.12^{\circ}$, $20.40^{\circ}$, and $30.28{ }^{\circ}$ for the (001), (002), and (110) planes, respectively. An additional impurity phase, $\mathrm{CaO}$, first appeared when the $\mathrm{Ca}^{2+}: \mathrm{Fe}^{3+}$ molar ratio reached 3:1. With a further increase in the $\mathrm{Ca}^{2+}: \mathrm{Fe}^{3+}$ molar ratio to $4: 1$, both $\mathrm{CaO}$ and $\mathrm{Ca}(\mathrm{OH})_{2}$ phases appeared (Supplementary Figure S1B). The calculated basal spacing values were $8.73,8.63$, and $8.57 \AA$ for $\mathrm{Ca}^{2+}: \mathrm{Fe}^{3+}$ molar ratios of $2: 1,3: 1$, and $4: 1$, respectively. The structural parameters and crystallite sizes of the $\mathrm{Ca}^{2+}: \mathrm{Fe}^{3+}$ LDH samples are listed in Table 1. The mean crystallite size (D) was estimated according to the Scherrer equation as (1) (Dorn, 1953):

$$
D=\frac{k \lambda}{\beta \cos \theta}
$$

where $\mathrm{K}$ is the shape factor, $\lambda$ is the $\mathrm{X}$-ray wavelength, $\beta$ is the full width at half maximum for a given diffraction peak after correcting for instrumental broadening, and $\theta$ is the Bragg angle of reflection.

As shown in Supplementary Figure S1B, when the coprecipitation reaction was performed at a $\mathrm{pH}$ less than 13 , no $\mathrm{CaFe}-\mathrm{LDH}$ crystallites were formed. With an increase in the initial $\mathrm{pH}$ to $14, \mathrm{CaFe}-\mathrm{LDH}$ interacted with the $(\mathrm{OH})^{-}$anion, exhibiting a lower crystallinity owing to an increase in the formation of impurities, including $\mathrm{Ca}(\mathrm{OH})_{2}$ and $\mathrm{Fe}(\mathrm{OH})_{3}$. The obtained results demonstrate that well-crystallized single-phase CaFe-LDHs can be synthesized at a $\mathrm{pH}$ of 13 .

\section{Structure Transformation of CaFe-LDOs With Thermal Decomposition}

Figure 1A shows the XRD patterns after the thermal treatment. In the $\mathrm{CaFe}-\mathrm{LDH}$ calcined at different temperatures, remarkable phase changes were observed. Specifically, the original structure of pristine LDHs was completely destroyed and transformed into $\mathrm{Ca}_{2} \mathrm{Fe}_{2} \mathrm{O}_{5}$ (JCPDS No. 47-1744) with an orthorhombic structure. $\mathrm{A} \mathrm{CaCO}_{3}$ (JCPDS No. 86-2339) impurity phase, indexed to a rhombohedral structure with a main diffraction peak at $2 \theta=$ $29.36^{\circ}$, was subsequently generated. As evident from the XRD patterns in Figure 1A, the $\mathrm{CaCO}_{3}$ phase only appeared when pristine LDHs were treated at $400^{\circ} \mathrm{C}$ under ambient conditions. However, when the C-400-LDO specimen was treated in Ar, no $\mathrm{CaCO}_{3}$ phase was formed (Supplementary Figure S2). This 
TABLE 1 | Structural parameters from XRD analysis of $\mathrm{CaFe}-\mathrm{LDH}$ s with different $\mathrm{Ca}^{2+}: \mathrm{Fe}^{3+}$ molar ratios.

\begin{tabular}{|c|c|c|c|c|c|c|}
\hline \multirow[t]{2}{*}{$\mathrm{Ca}^{2+}: \mathrm{Fe}^{3+}$} & \multirow[t]{2}{*}{$d_{(001)}(\AA)$} & \multirow[t]{2}{*}{$d_{(002)}(\AA)$} & \multirow[t]{2}{*}{$d_{(110)}(\AA)$} & \multirow{2}{*}{$\begin{array}{l}\text { Lattice parameters } \\
\text { (Å) }\end{array}$} & \multicolumn{2}{|c|}{ Crystallite size (nm) } \\
\hline & & & & & (001) & (110) \\
\hline $2: 1$ & 8.73 & 4.35 & 2.95 & 8.61 & 28.45 & 29.36 \\
\hline $4: 1$ & 8.57 & 4.32 & 2.95 & 8.65 & 14.23 & 34.25 \\
\hline
\end{tabular}
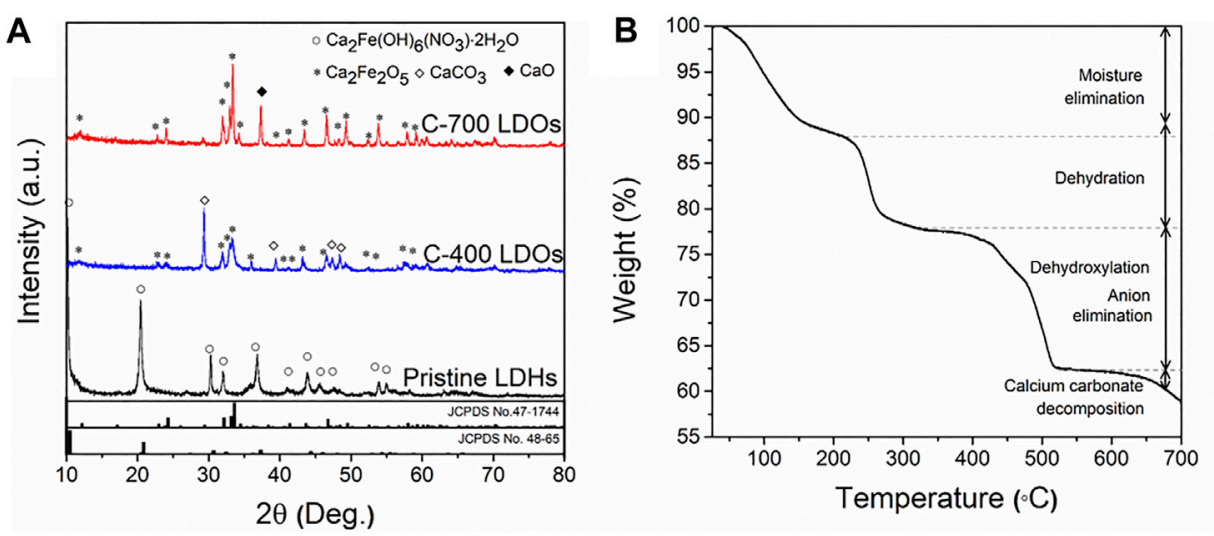

FIGURE 1 | (A) XRD patterns of Pristine LDHs, C-400 LDOs, and C-700 LDOs with different structural transformations and (B) TGA spectrum.

finding suggests that $\mathrm{CaCO}_{3}$ formation is related to $\mathrm{CO}_{2}$ dissolution from the air during the calcination process. As the calcination temperature increased, the $\mathrm{CaCO}_{3}$ phase disappeared, and the crystallization of the $\mathrm{CaO}$ phase increased. When the temperature exceeded $550^{\circ} \mathrm{C}$, decomposition occurred (BabouKammoe et al., 2012; Yamaguchi et al., 2015). The disappearance of $\mathrm{CaCO}_{3}$ can be explained by the following reaction:

$$
\mathrm{CaCO}_{3(s)} \rightarrow \mathrm{CaO}_{(s)}+\mathrm{CO}_{2}(g)
$$

TGA data were acquired to explore the thermal decomposition of the synthesized CaFe-LDHs. The results are shown in Figure 1B. Four major weight loss stages were observed. The first weight loss stage $(11.7 \mathrm{wt} \%)$ occurred from room temperature to $200^{\circ} \mathrm{C}$ and corresponds to the loss of weakly adsorbed water molecules on the crystallite surface. During the second stage of weight loss (9.9 wt\%) between 200 and $300^{\circ} \mathrm{C}$, the intercalated crystallized water between the cationic layers was removed. The third stage of weight loss (15.86 wt\%), which occurred from 300 to $550^{\circ} \mathrm{C}$, was associated with the thermal decomposition of hydroxyl $\left(\mathrm{OH}^{-}\right)$groups anchored to transition metal oxides and anionic $\left(\mathrm{NO}_{3}{ }^{-}\right)$species (Mahjoubi et al., 2017). Finally, the last stage of weight loss (3.7 wt $\%$ ), which appeared at temperatures above $550^{\circ} \mathrm{C}$, was attributed to the decomposition of calcium carbonate $\left(\mathrm{CaCO}_{3}\right)$, as displayed in Supplementary Figure S3.

The FT-IR spectra of the CaFe-LDH samples were analyzed to identify structural transformations via comparisons of chemical bonding involving various functional groups (Supplementary Figure S4). The characteristic peaks appearing at $1,640 \mathrm{~cm}^{-1}$ are assigned to the $\mathrm{H}-\mathrm{O}-\mathrm{H}$ bending vibrations of interlayer molecular water, whereas the characteristic sharp absorption band around $1,350 \mathrm{~cm}^{-1}$ is associated with the antisymmetric stretching mode of $\mathrm{NO}_{3}{ }^{-}$in the interlayer (Supplementary Figure S4B). The intense broad bands observed at approximately $3,585 \mathrm{~cm}^{-1}$ are associated with the stretching vibrations of the structural $\left(\mathrm{OH}^{-}\right)$ groups in $\mathrm{Ca}(\mathrm{OH})_{2}$ and $\mathrm{Fe}(\mathrm{OH})_{2}$ (Supplementary Figure $\mathrm{S} 4 \mathrm{C}$ ). The peaks at 749 and $580 \mathrm{~cm}^{-1}$ are attributed to the stretching vibrations of either $\mathrm{Ca}-\mathrm{O}$ or Fe-O (Metal-O) in the lattice, as shown in Supplementary Figure S4D (Wu et al., 2012; Mahjoubi et al., 2017). The band at $1,640 \mathrm{~cm}^{-1}$ disappeared completely after calcination in the case of C-400 LDO because the crystallized water molecules were removed. In addition, the gradual decrease in the $\mathrm{NO}_{3}{ }^{-}$stretching vibration intensity at $1,350 \mathrm{~cm}^{-1}$ implies the decomposition of $\mathrm{NO}_{3}{ }^{-}$anions due to an increase in the calcination temperature; complete decomposition occurred in the C-700 LDO sample. A noticeable decrease in peaks corresponding to the $\mathrm{OH}^{-}$group in the case of $\mathrm{C}-400 \mathrm{LDO}$ implies that the $\mathrm{OH}^{-}$ species of the $\mathrm{Ca}(\mathrm{OH})_{2}$ and $\mathrm{Fe}(\mathrm{OH})_{2}$ cationic layers were decomposed when the thermal treatment temperature exceeded $400^{\circ} \mathrm{C}$. The subsequent increase in the intensity of the metal-O peaks at 749 and $580 \mathrm{~cm}^{-1}$ indicates that the structure of the pristine $\mathrm{LDHs}$ was transformed into that of the respective metal oxides. Peaks corresponding to commercial $\mathrm{CaCO}_{3}$ appeared at $1,394 \mathrm{~cm}^{-1}\left(v^{3}\right.$ asymmetric $\left.\mathrm{CO}_{3}{ }^{2-}\right)$ and $871 \mathrm{~cm}^{-1}\left(v^{2}\right.$ asymmetric $\mathrm{CO}_{3}{ }^{2-}$ ) (Butto et al., 2018). The intensity of these bands decreased with increasing calcination temperature. Thus, according to the XRD and TGA findings, a structural transformation occurred in the C-400 LDO specimen. 

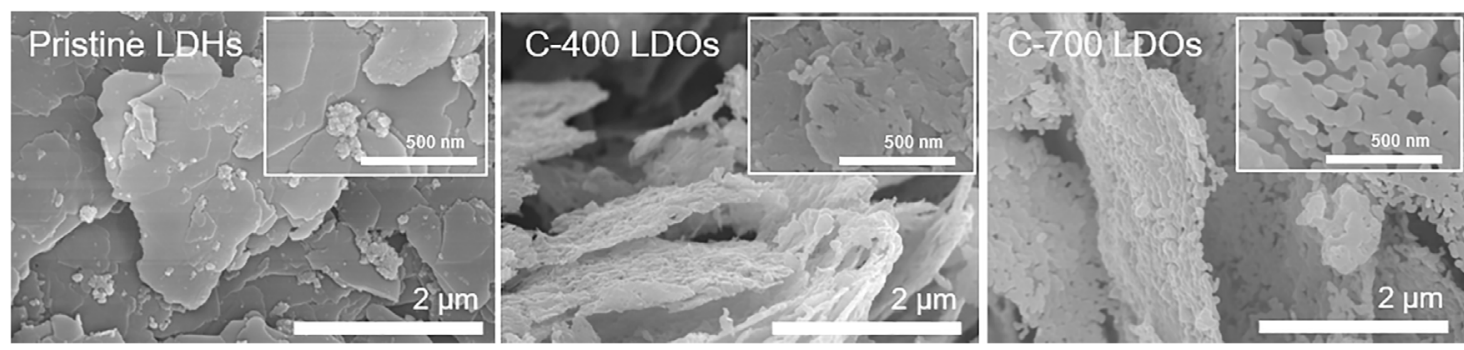

FIGURE 2 | SEM images of (A) Pristine LDHs, (B) C-400 LDOs and (C) C-700 LDOs.
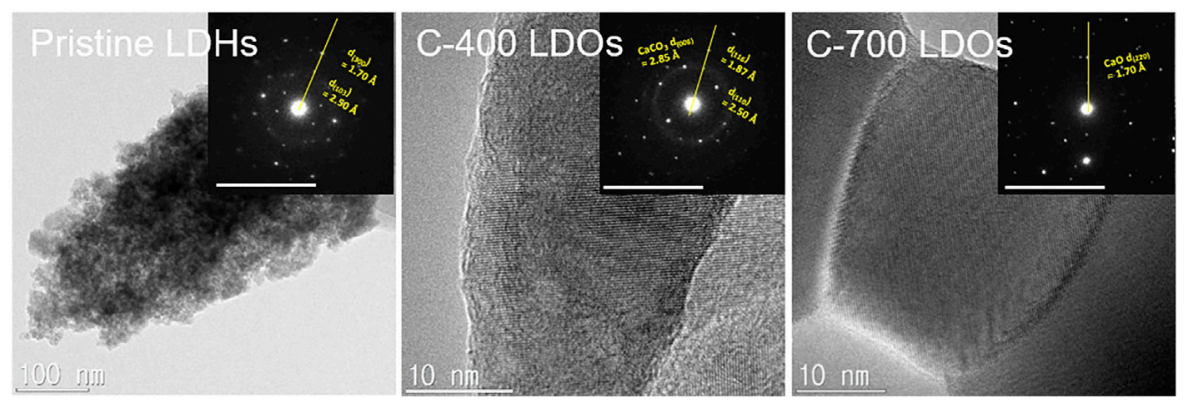

FIGURE 3 | TEM images and SAED patterns of (A) Pristine LDHs, (B) C-400 LDOs, and (D) C-700 LDOs.

Figure 2 shows SEM images of the CaFe-LDHs for different thermal treatment conditions. A comparison of the CaFe-LDHs with pristine LDHs revaled transformed morphology in C-400 LDOs. Such a phenomenon is influenced by the destruction of anion layers with the removal of crystalline water molecules. The C-700 LDOs specimen presented a morphology consisting primarily of individual spherical particles.

Figure 3 displays the TEM images and the associated selected area electron diffraction (SAED) patterns obtained for the CaFe$\mathrm{LDH}$ samples. The pristine LDHs showed the typical crystallographic layered structure of $\mathrm{CaFe}-\mathrm{LDH}$, including (300) and (103) planes with lattice constants of $1.70 \AA$ and $2.50 \AA$, respectively. For C-400 LDOs, the presence of the (006), (110), and (116) planes corresponding to rhombohedral $\mathrm{CaCO}_{3}$ was detected after thermal treatment at $400^{\circ} \mathrm{C}$. In the case of calcination at $700^{\circ} \mathrm{C}$, only the $\mathrm{CaO}$ phase was identified in the $\mathrm{XRD}$ pattern (Figure 1A). Here, $\mathrm{CaO}$ is a unique by-product formed as a result of thermal treatment. The obtained SAED patterns confirm the occurrence of gradual structural and crystallographic transformations as a function of temperature from 400 to $700^{\circ} \mathrm{C}$.

\section{Adsorption Performance of Chloride in Aqueous Solution}

Experiments were conducted to investigate the removal of chloride ions, which may shorten the lifespan of building structures. Figures $4 \mathrm{~A}, \mathrm{~B}$ show the results obtained for the removal of chloride at different adsorption times and a fixed ion adsorption time of $60 \mathrm{~min}$, respectively. The percentage removal efficiency was estimated according to Equation (3).

$$
\text { Removal }(\%)=\frac{C_{0}-C_{e}}{C_{0}} \times 100
$$

where $C_{0}$ and $C_{e}$ are the initial and equilibrium anion concentrations $(\mathrm{mg} / \mathrm{L})$, respectively.

As shown in Figure 4A, the removal percentages of pristine LDHs, C-400 LDOs, and C-700 LDOs were 11.49, 16.98, and $57.90 \%$, respectively, for an adsorption time of $5 \mathrm{~min}$ at the initial stage of the reaction. The amount of adsorbed chloride increased rapidly over $5 \mathrm{~min}$, with a gradual increase up to $60 \mathrm{~min}$ before reaching steady-state equilibrium. The removal percentages for a $60 \mathrm{~min}$ adsorption time were $13.41 \%$ for pristine LDHs, $29.25 \%$ for C-400 LDOs, and 79.62\% for C-700 LDOs. Based on the obtained findings, the removal efficiency with C-700 LDOs was almost six times higher than that of pristine LDHs, suggesting outstanding performance in terms of chloride removal.

The FT-IR spectra of the sample upon the adsorption of chloride ions are illustrated in Supplementary Figure S5. The characteristic sharp absorption band at approximately $1,360 \mathrm{~cm}^{-1}$ is associated with the antisymmetric stretching mode of chloride in the interlayer. In addition, in the cases of C-400 LDOs and C700 LDOs without anion adsorption, typical $\mathrm{H}-\mathrm{O}-\mathrm{H}$ peaks corresponding to bending vibrations $\left(1,640 \mathrm{~cm}^{-1}\right)$ and stretching vibrations $\left(3,585 \mathrm{~cm}^{-1}\right)$ induced by $(\mathrm{OH})^{-}$groups were removed (see comment in Supplementary Figure S4). However, the adsorption peaks reappeared after chloride adsorption due to the recovery of $(\mathrm{OH})^{-}$groups and crystalline 

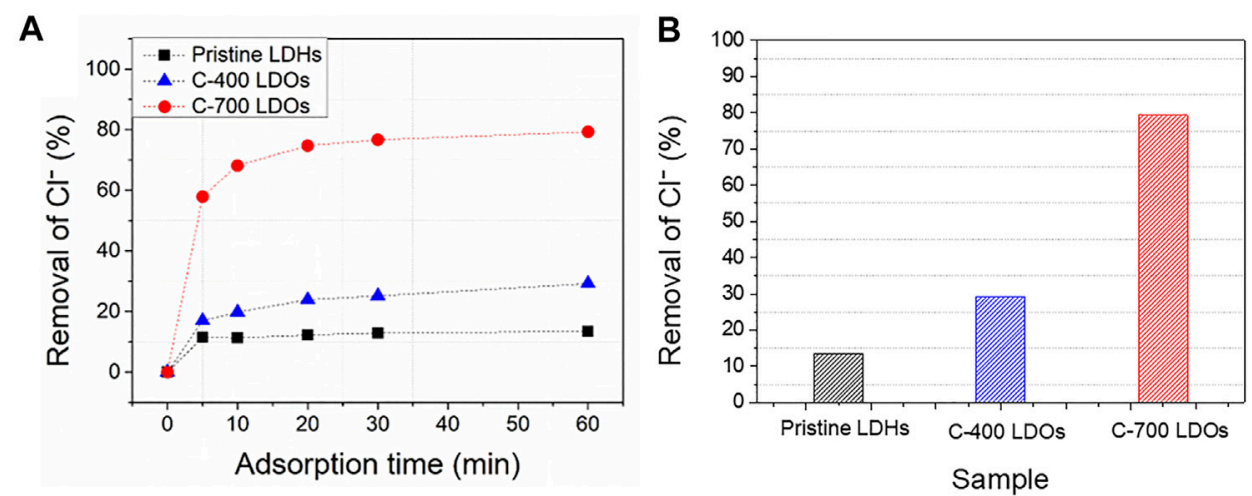

FIGURE 4 | lon chromatography of CaFe-LDHs chloride removal (\%) at (A) different adsorption times and (B) a fixed adsorption time of 60 min.

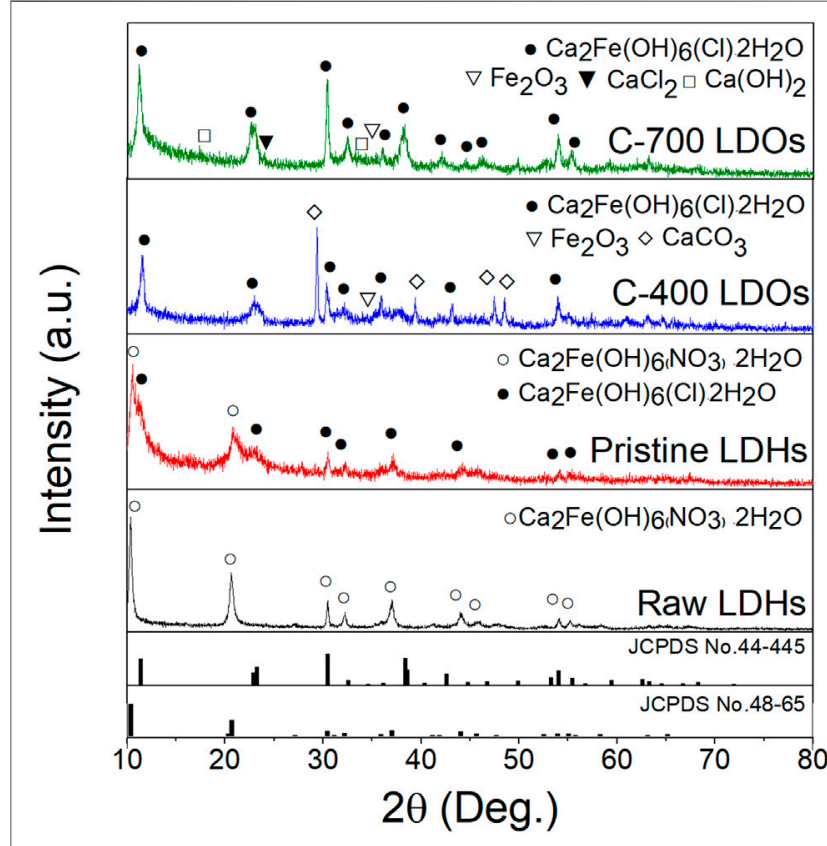

FIGURE 5|XRD patterns of before the chloride adsorption (Raw LDHs), Pristine LDHs, C-400 LDOs, and C-700 LDOs after chloride adsorption.

water molecules during the reconstruction process in an aqueous atmosphere. Hence, the results provide evidence for both the reconstruction processes and the successful adsorption of chloride ions by CaFe-LDOs.

The reconstructed CaFe-LDHs and LDOs after $60 \mathrm{~min}$ of chloride adsorption were characterized by XRD. The results are shown in Figure 5. Characteristic peaks that were typical of CaFe-LDHs were indexed to the rhombohedral structure for all $\mathrm{LDH}$ samples, including those from the (006) and (0012) planes after the adsorption of chloride ions. Upon chloride adsorption, the XRD patterns of the crystalline $\mathrm{LDHs}$ corresponded to a structure with a chemical formula $\mathrm{Ca}_{2} \mathrm{Fe}(\mathrm{OH})_{6}(\mathrm{Cl}) \cdot 2 \mathrm{H}_{2} \mathrm{O}$ (JCPDS No.44-445). The crystallinity of the CaFe-LDHs simultaneously decreased with anion adsorption due to the reconstruction phenomenon (i.e., memory effect). Furthermore, the basal spacing increased, and the $2 \theta$ angle associated with the (006) XRD peak increased from $10.36^{\circ}\left(\mathrm{NO}_{3}{ }^{-}\right)$to $11.32^{\circ}$ (chloride) because the ionic radius of the chloride ion (1.75 $\AA$ ) is smaller than that of $\mathrm{NO}_{3}{ }^{-}(1.79 \AA)$. The chloride ion was partially substituted with $\mathrm{NO}_{3}{ }^{-}$present in the interlayer, which led to the formation of two types of interstratified pristine LDHs. The preadsorption data are shown in Figure 1A. The XRD pattern of the post-adsorption C-400 LDOs also included secondary crystalline phases of $\mathrm{CaCO}_{3}\left(2 \theta=29.36^{\circ}\right)$ even after particle reconstruction because $\mathrm{CaCO}_{3}$ is a basic salt with very low solubility. Therefore, the layered $\mathrm{CaFe}$ - LDOs reconstructed via refolding in aqueous solution could exchange chloride anions due to the reconstruction of $\mathrm{Ca}_{2} \mathrm{Fe}_{2} \mathrm{O}_{5}$ as follows (4):

$$
\begin{gathered}
\mathrm{Ca}_{2} \mathrm{Fe}_{2} \mathrm{O}_{5}+2 \mathrm{CaCO}_{3}+\mathrm{Cl}^{-}+5.5 \mathrm{H}_{2} \mathrm{O} \rightarrow \mathrm{Ca}_{2} \mathrm{Fe}(\mathrm{OH})_{6}(\mathrm{Cl}) \\
\cdot 2 \mathrm{H}_{2} \mathrm{O}+0.5 \mathrm{Fe}_{2} \mathrm{O}_{3}+2 \mathrm{CaCO}_{3}+\mathrm{OH}^{-}
\end{gathered}
$$

In particular, the CaFe-LDOs prepared after thermal treatment at $700^{\circ} \mathrm{C}$ showed the pure crystalline structure of $\mathrm{CaFe}-\mathrm{LDH}$ with individual interlayer anions of $\mathrm{Cl}^{-}, \mathrm{Ca}(\mathrm{OH})_{2}$, and $\mathrm{CaCl}_{2}$. This was because the secondary crystalline phase of $\mathrm{CaO}$ (see Figure 1A) after anion adsorption was transformed to $\mathrm{Ca}(\mathrm{OH})_{2}$ via hydrolysis in solution. The results suggest adsorption from partial $\mathrm{Ca}(\mathrm{OH})_{2}$ phases to $\mathrm{CaCl}_{2}$. Therefore, the C-700 LDOs sample undergoes the following chemical reaction when reconstructed in water containing chloride (5):

$$
\begin{gathered}
\mathrm{Ca}_{2} \mathrm{Fe}_{2} \mathrm{O}_{5}+2 \mathrm{CaO}+4 \mathrm{Cl}^{-}+7.5 \mathrm{H}_{2} \mathrm{O} \rightarrow \mathrm{Ca}_{2} \mathrm{Fe}(\mathrm{OH})_{6}(\mathrm{Cl}) \\
\cdot 2 \mathrm{H}_{2} \mathrm{O}+0.5 \mathrm{Fe}_{2} \mathrm{O}_{3}+0.5 \mathrm{Ca}(\mathrm{OH})_{2}+1.5 \mathrm{CaCl}_{2}+4 \mathrm{OH}^{-}
\end{gathered}
$$

This mechanism was induced by the following factors: 1) anion capture by reconstruction, 2) capture by chemical reaction with metal oxide, and 3) physical adsorption. The C-700 LDOs can capture $4 \mathrm{~mol}$ of $\mathrm{Cl}^{-}$(see Eq. (5)). Here, $1 \mathrm{~mol}$ of $\mathrm{Cl}^{-}$was captured by intercalation between cationic layers during the refolding process, and additional $3 \mathrm{~mol}$ of $\mathrm{Cl}^{-}$were captured by chemical reaction with $\mathrm{CaO}$, which was generated during thermal treatment at $700^{\circ} \mathrm{C}$. This metal oxide moiety, initiated by pristine-LDHs, also captures $\mathrm{Cl}^{-}$by chemical reactions other than capture by the refolding process, which cannot be realized even 

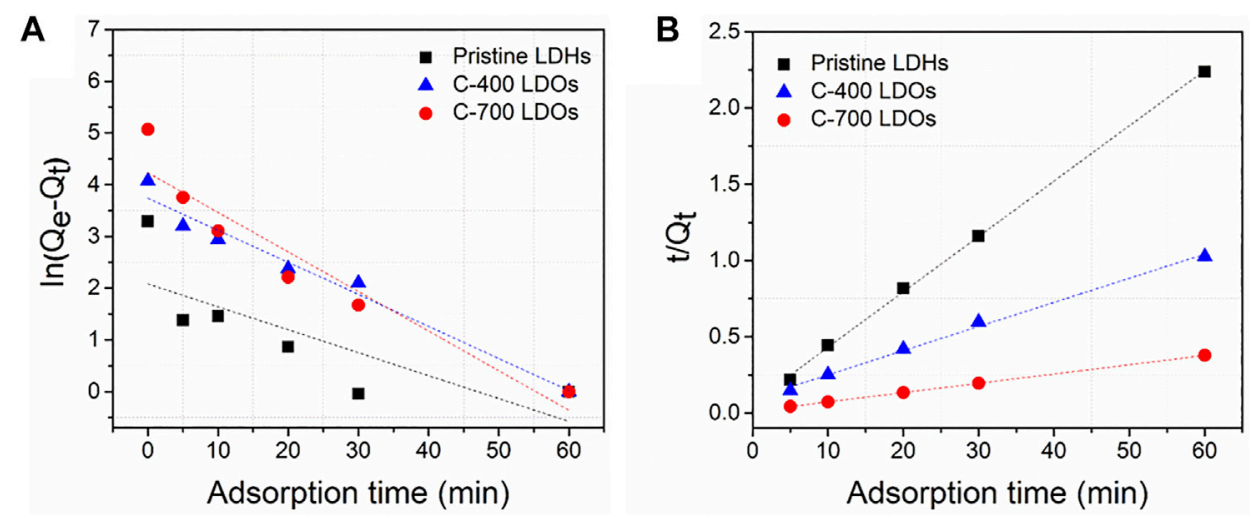

FIGURE 6 | (A) Pseudo-first-order and (B) pseudo-second-order kinetic plots for the sorption of chloride on Pristine LDHs, C-400 LDOs and C-700 LDOs.

after the calcination of typical LDHs (Wu et al., 2012; Halajnia et al., 2013; Zhou et al., 2015). Supplementary Figure S6 shows SEM images of the reconstructed pristine LDHs, C-400 LDOs, and C-700 LDOs before (top) and after anion adsorption (bottom). Although no significant changes were observed for the reconstructed LDHs, differences in morphology between the pristine LDHs and C-700 LDOs are evident. Although the morphologies of pristine LDHs before and after anion adsorption appear to be similar, the post-anion adsorption C700 LDOs exhibit larger plate-like particles aggregated into flowerlike shapes. Such a microstructure may be attributed to the change in the crystallinity of the remaining $\mathrm{Ca}(\mathrm{OH})_{2}$ phases, as expressed by Eq. 9. The removal of chloride ions by CaFe-LDOs particles could be influenced by structural tuning. In particular, the $\mathrm{CaFe}-$ LDOs exhibited different efficiencies (\%) for anion removal, which could be enhanced by using CaFe-LDOs rather than pristine LDHs.

\section{Adsorption Kinetics and Equilibrium Sorption Measurements and Modeling}

To investigate the difference in anion adsorption by the CaFeLDHs and LDOs, the adsorption kinetics of chloride ions onto the CaFe-LDHs and LDOs were fitted to a linearized form of pseudofirst-order (Eq. 6) and pseudo-second-order (Eq. 7) models based on experimental data (Calisto et al., 2019; Rathee et al., 2019):

$$
\begin{gathered}
\ln \left(Q_{e}-Q_{t}\right)=\ln Q_{e}-k_{1} t \\
\frac{t}{Q_{t}}=\frac{1}{k_{2} Q_{e}^{2}}+\frac{t}{Q_{e}}
\end{gathered}
$$

where $Q_{e}$ and $Q_{t}$ denote the amounts of anions adsorbed $(\mathrm{mg} / \mathrm{g})$ per unit of LDHs and LDOs at equilibrium and at a specified time $t$ (min), respectively; and $k_{1}$ and $k_{2}$ denote the pseudo-first-order and pseudo-second-order rate constants, respectively. Pseudofirst-order (Figure 6A) and pseudo-second-order (Figure 6B) plots for the sorption of anions by CaFe-LDHs and LDOs as a function of adsorption time are depicted in Figure 6. The specific model parameters obtained for chloride ion concentrations are listed in Table 2 . The correlation coefficients $\left(R^{2}\right)$ were compared to determine the adequate kinetic model for the quantitative evaluation. Among the experimental data, the chloride ion adsorption kinetics were only slightly fitted to the pseudosecond-order plot and did not follow the pseudo-first-order plot. In contrast, well-fit kinetics were observed when the data were evaluated using a pseudo-second-order plot. As shown in Table 2, the high correlation coefficient values $\left(R^{2}\right)$ obtained for all the LDH and LDO adsorbent samples confirm that the pseudosecond-order model describing the chloride ion kinetics is wellfitted when compared to the pseudo-first-order model (Zaghouane-Boudiaf et al., 2011). Therefore, chemisorption, which typically involves electrostatic attraction and chemical bonding between the adsorbate and adsorbent, is responsible for the immobilization of chloride ions on CaFe-LDHs and LDOs.

The aim of adsorption isotherms is to correlate the adsorbate concentration in the solution with the adsorbed content of metal ions at the adsorbate-to-adsorbent interface. Langmuir (Figure 7A) and Freundlich (Figure 7B) isotherm models are crucial for the design of sorption systems. The adsorption of chloride ions onto $\mathrm{CaFe}-\mathrm{LDH}$ and $\mathrm{LDO}$ adsorbents was investigated, and the applicability of the aforementioned isotherms was examined. The Langmuir model assumes a homogenous surface via monolayer adsorption between the adsorbed ions, and the Langmuir isotherm represents the equilibrium distribution of sorbate between the solid and liquid phases. This isotherm is often expressed as Equation 8 (Yan et al., 2016; Mu'azu et al., 2018):

$$
Q_{e}=\frac{Q_{\max } K_{L} C_{e}}{1+K_{L} C_{e}}
$$

where $C_{e}\left(\mathrm{mg} \cdot \mathrm{L}^{-1}\right)$ denotes the concentration of sorbate at equilibrium, $Q_{e}\left(\mathrm{mg} \cdot \mathrm{g}^{-1}\right)$ denotes the amount of sorbate per mass of sorbent at equilibrium, $K_{L}\left(\mathrm{~L} \cdot \mathrm{mg}^{-1}\right)$ represents the equilibrium constant related to the sorption energy between the sorbate and sorbent, and $Q_{\max }$ denotes the limiting amount of sorbate that can be taken per mass of sorbent.

The Freundlich equation can be utilized to estimate the sorption intensity of the sorbent toward the sorbate, and is expressed by Equation 9 (Peng et al., 2015; Santos R. M. M.d. et al., 2017): 
TABLE 2 | Coefficients of pseudo-first-order and pseudo-second-order parameters for chloride adsorption by pristine LDHs, C- 400 LDOs, and C-700 LDOs.

LDHs

\begin{tabular}{lccc} 
& $\boldsymbol{K}_{\mathbf{1}}\left(\mathbf{m i n}^{-\mathbf{1}}\right)$ & $\boldsymbol{Q}_{\mathbf{e}}(\mathbf{p p m})$ & $\boldsymbol{R}^{\mathbf{2}}$ \\
\hline Pristine LDHs & 0.0443 & 13.1113 & 0.5374 \\
C-400 LDHs & 0.0620 & 41.3215 & 0.9663 \\
C-700 LDHs & 0.0765 & 93.5092 & 0.8970
\end{tabular}

Pseudo-second-order kinetic parameters

\begin{tabular}{ccc}
\hline $\boldsymbol{K}_{\mathbf{2}}\left(\mathbf{p p m} \mathbf{- 1}^{\mathbf{1}} \mathbf{m i n}^{\mathbf{- 1}}\right)$ & $\boldsymbol{Q}_{\boldsymbol{e}}$ (ppm) & $\boldsymbol{R}^{\mathbf{2}}$ \\
0.0363 & 27.5460 & 0.9991 \\
0.0158 & 63.2302 & 0.9950 \\
0.0061 & 164.0372 & 1
\end{tabular}
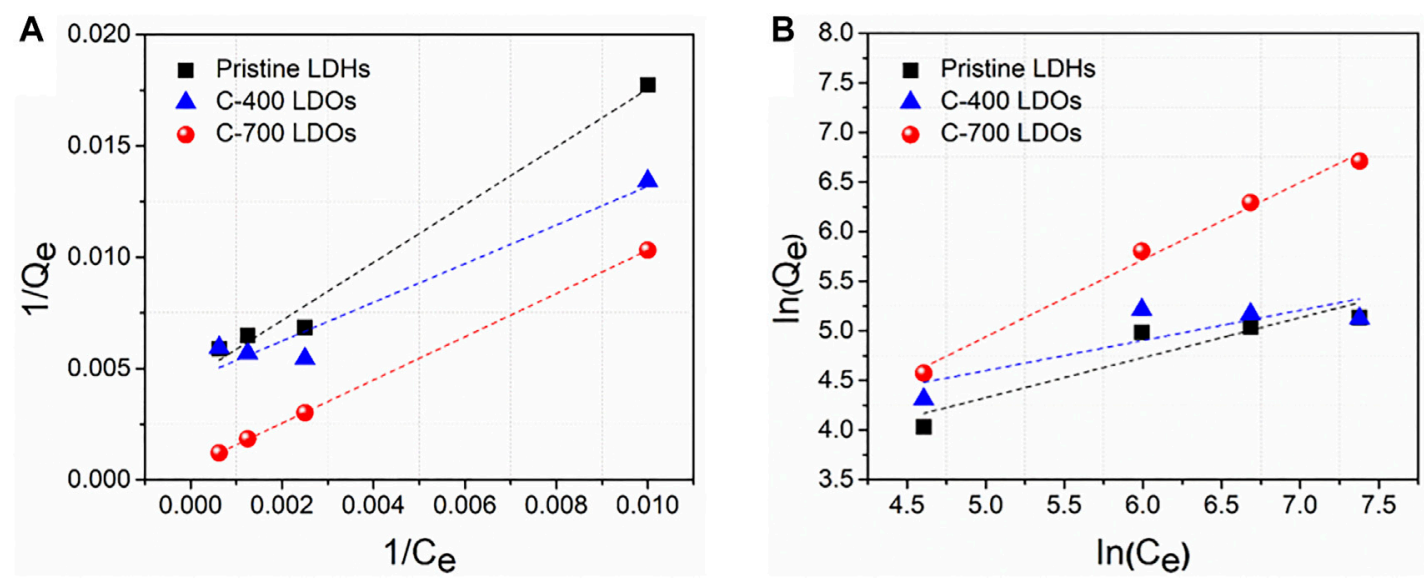

FIGURE 7 | (A) Langmuir and (B) Freundlich plots for the sorption of chloride onto Pristine LDHs, C-400 LDOs, and C-700 LDOs.

TABLE 3 | Langmuir and Freundlich isotherm parameters for chloride adsorption by pristine LDHs, C- 400 LDOs, and C-700 LDOs.

\begin{tabular}{|c|c|c|c|c|c|c|}
\hline \multirow[t]{2}{*}{ LDHs } & \multicolumn{3}{|c|}{ Langmuir isotherm parameters } & \multicolumn{3}{|c|}{ Freundlich isotherm parameters } \\
\hline & $K_{L}\left(\mathrm{~L} \cdot \mathrm{mg}^{-1}\right)$ & $Q_{\max }(\mathrm{mg})$ & $R^{2}$ & $K_{F}\left(\mathrm{~L} \cdot \mathrm{mg}^{-1}\right)$ & $n$ & $R^{2}$ \\
\hline Pristine LDHs & 0.0108 & 78.9704 & 0.9793 & 3.9992 & 1.8914 & 0.7935 \\
\hline C-400 LDHs & 0.0043 & 110.2291 & 0.9203 & 17.9987 & 3.0321 & 0.5468 \\
\hline C-700 LDHs & 0.0006 & 881.8342 & 0.9999 & 3.1183 & 1.3050 & 0.9882 \\
\hline
\end{tabular}

$$
Q_{e}=K_{F} C_{e}^{1 / n}
$$

where $Q_{e}\left(\mathrm{mg}^{-1} \mathrm{~g}^{-1}\right)$ denotes the amount of adsorbed anions, $C_{e}$ denotes the equilibrium concentration, and $K_{F}$ and $n$ are constants incorporating all parameters affecting the sorption process, such as the sorption capacity and intensity. The isotherm constants in Equations 8, 9, as well as the correlation coefficients $\left(R^{2}\right)$, are listed in Table 3. Based on all the $R^{2}$ values of the LDH and LDO samples and the maximum capacities, the equilibrium data fit the Langmuir isotherm with a high correlation coefficient, indicating monolayer sorption of chloride ions onto $\mathrm{CaFe}-\mathrm{LDH}$ and LDOs. In particular, the Langmuir parameters are $\mathrm{Qmax}=$ $78.97 \mathrm{mg} / \mathrm{g}$ for pristine LDHs, Qmax $=110.23 \mathrm{mg} / \mathrm{g}$ for C400 LDOs, and $\mathrm{Qmax}=881.83 \mathrm{mg} / \mathrm{g}$ for C-700 LDOs. The removal of chloride anions by different LDHs and LDOs has been studied in recent years, and some reports have provided the uptake capacity for chloride anions. Table $\mathbf{4}$ shows that the uptake capacity obtained in this study was larger than that reported in previous research.

\section{Corrosion of Iron Alloys in Aqueous Solution With and Without LDHs}

To study the anti-corrosion effects of CaFe-LDHs and LDOs on iron alloys from destructive chloride anions, potentiodynamic measurements of the exponential dependence of the current on voltage deviations were conducted in an aqueous $3.5 \mathrm{wt} \% \mathrm{NaCl}$ solution; the results are depicted in Figure 8. The variations in the electrochemical kinetic parameters, such as the corrosion current $\left(\mathrm{I}_{\text {corr }}\right)$ and corrosion rate (CR), were determined from the curves using the extrapolation method (as plotted in Figure 8 and supplemented by Table 5).

The corrosion rates $\left(\mathrm{mm} \mathrm{year}^{-1}\right)$ obtained from the polarization were calculated using Equation 10:

$$
C R=\frac{I_{\text {corr }} \times K \times E W}{\rho \times A}
$$

Here, EW denotes the equivalent weight of $\mathrm{Fe}(27 \mathrm{~g}), \mathrm{K}$ represents the corrosion rate constant $\left(3,272 \mathrm{~mm}_{\text {year }}{ }^{-1} \mathrm{~A}^{-1} \mathrm{~cm}^{-1}\right)$, denotes the 
TABLE 4 | Comparison of LDHs removal capacity for chloride anions obtained in this work and in previous reports.

\begin{tabular}{|c|c|c|}
\hline LDH sorbent & Removal capacity (mg/g) & Reference \\
\hline Pristine LDHs & 78.9704 & This work \\
\hline C-400 LDHs & 110.2291 & \\
\hline C-700 LDHs & 881.8342 & \\
\hline MgAl LDHs & $257.00 \mathrm{mg} / \mathrm{g}$ & Materials Chemistry and Physics, 2014, 145, 376e386 \\
\hline MgAl LDHs & $168.00 \mathrm{mg} / \mathrm{g}$ & Water research, 2006, 40, 735-743 \\
\hline MgAl LDHs & $149.50 \mathrm{mg} / \mathrm{g}$ & Desalination and Water Treatment, 2011, 36, 50-56 \\
\hline MgAl LDHs & $128.20 \mathrm{mg} / \mathrm{g}$ & Corrosion Science, 2019, 152, 120-129 \\
\hline MgAl LDHs & $122.20 \mathrm{mg} / \mathrm{g}$ & Chemosphere, 2018, 209, 721-729 \\
\hline MgAl LDHs & $115.50 \mathrm{mg} / \mathrm{g}$ & Journal of Hazardous Materials, 2015, 300, 475-482 \\
\hline CaAl LDHs & $105.90 \mathrm{mg} / \mathrm{g}$ & Desalination, 2020, 474, 114,186 \\
\hline CaAl LDHs & $105.00 \mathrm{mg} / \mathrm{g}$ & Construction and Building Materials, 2015, 93, 1,051-1,058 \\
\hline MgAl LDHs & $33.54 \mathrm{mg} / \mathrm{g}$ & Applied Clay Science, 2020, 187, 105,495 \\
\hline
\end{tabular}

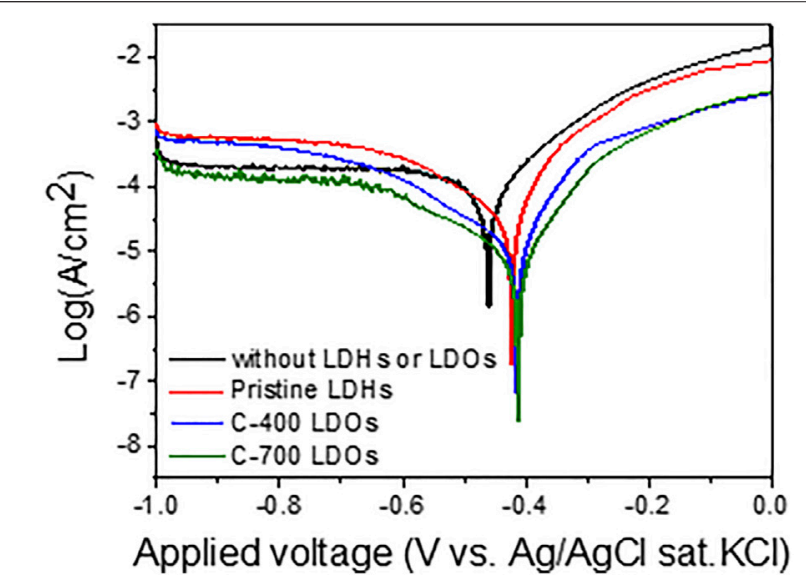

FIGURE 8 | Potentiodynamic polarization (PDP) curves obtained in a 3.5 wt\% $\mathrm{NaCl}$ solution without LDHs or LDOs and with Pristine LDHs, C-400 LDOs, and C-700 LDOs.

density of $\mathrm{Fe}\left(7.874 \mathrm{gcm}^{-3}\right)$, and $\mathrm{A}\left(\mathrm{cm}^{2}\right)$ denotes the surface area of the electrode.

The CR for iron alloys with the application of C-700 LDHs was $89.28 \times 10^{-3} \mathrm{~mm} /$ year, whereas the CR in the case without LDHs and LDOs was $2390.69 \times 10^{-3} \mathrm{~mm} /$ year. These findings indicate that when iron alloys are placed in a severe atmosphere with a high concentration of chlorides in solution, the speed of corrosion is accelerated to a maximum of 26.7 times over a year unless the iron alloys are not protected. As can be seen from the results of the Nyquist plot for iron alloys upon the application of $\mathrm{CaFe}-\mathrm{LDH}$ and LDOs (Figure 9A), the mitigation of corrosion led to a clear increase in the diameter of the capacitive loop. The diameter of the semicircle was also significantly enlarged for the protective LDH and LDO samples containing more charge-transfer resistance, as confirmed by the Bode plots in Figure 9B. To quantitatively determine the effects of various factors, including the addition of CaFe-LDHs and LDOs, immersion time, and chloride content, a numerical simulation must be employed to fit the obtained EIS results. Because the degree of chloride removal from the solution containing the iron alloy specimen is an indicator of corrosion protection, the equivalent circuit model constants in Figure 9D were applied. In the equivalent circuit model, iron alloys are considered to have a porous structure and exhibit capacitive behavior (Hou et al., 2019; Imanieh and Afshar, 2019; Liu et al., 2019; Xu et al., 2020). The relevant parameters are listed in Table 6, where $R_{s}$ denotes the electrolyte resistance, $\mathrm{R}_{\mathrm{f}}$ denotes the electrolyte resistance inside the pores, $\mathrm{C}_{\mathrm{f}}$ represents the film capacitance, $\mathrm{R}_{\mathrm{ct}}$ represents the charge transfer resistance of the electrochemical processes occurring inside the pores, and $\mathrm{C}_{\mathrm{dl}}$ denotes the double-layer capacitance. The $\mathrm{C}_{\mathrm{dl}}$ value for pristine $\mathrm{LDH}$ s was $3.26 \times 10^{-3}\left(\mu \mathrm{F} \cdot \mathrm{cm}^{-2}\right)$, and this parameter generally decreased with higher-temperature heat treatment; the $\mathrm{C}_{\mathrm{dl}}$ values of C-400 LDOs and C-700 LDOs were $2.65 \times 10^{-3}\left(\mu \mathrm{F} \cdot \mathrm{cm}^{-2}\right)$ and $2.45 \times 10^{-3}\left(\mu \mathrm{F} \cdot \mathrm{cm}^{-2}\right)$, respectively. This phenomenon can be explained according to the Helmholtz model, where $C_{\mathrm{dl}}$ is expressed as follows (11) [15]:

$$
C_{d l}=\frac{\varepsilon_{r} \varepsilon_{0}}{d} \mathrm{~S}
$$

where $S$ denotes the exposed surface area of the steel specimen, $d$ represents the thickness of the double layer, $\varepsilon_{\mathrm{r}}$ denotes the dielectric constant of the electrolyte inside the capacitor, and $\varepsilon_{0}$ denotes the vacuum dielectric constant. Here, an increase in $C_{\mathrm{dl}}$ indicates an increase in the exposed surface area of the bare iron alloys by corrosion. The addition of LDHs and LDOs decreases the aggressive chlorination reaction (see Equations 1-4 and

TABLE 5 | Electrochemical polarization parameters and calculated corrosion rates (mm/year) in a 3.5 wt\% NaCl solution with and without LDHs or LDOs.

\begin{tabular}{|c|c|c|c|c|c|}
\hline Sample & Parameter $E_{\text {corr }}(\mathrm{mV})$ & $I_{\text {corr }}(\mu \mathrm{A})$ & $B_{a}\left(\mathrm{mV} \mathrm{dec}{ }^{-1}\right)$ & $\begin{array}{c}B_{c}(m V \\
\left.\operatorname{dec}^{-1}\right)\end{array}$ & $C R$ (mm/year) \\
\hline Without LDHs & -461.21 & 206.04 & 188.11 & 350.14 & $2390.69 \times 10^{-3}$ \\
\hline Pristine LDHs & -423.175 & 34.978 & 64.61 & 190.67 & $405.85 \times 10^{-3}$ \\
\hline C-400 LDHs & -415.179 & 12.225 & 71.23 & 179.18 & $141.85 \times 10^{-3}$ \\
\hline C-700 LDHs & -411.107 & 7.695 & 80.62 & 174.4 & $89.28 \times 10^{-3}$ \\
\hline
\end{tabular}



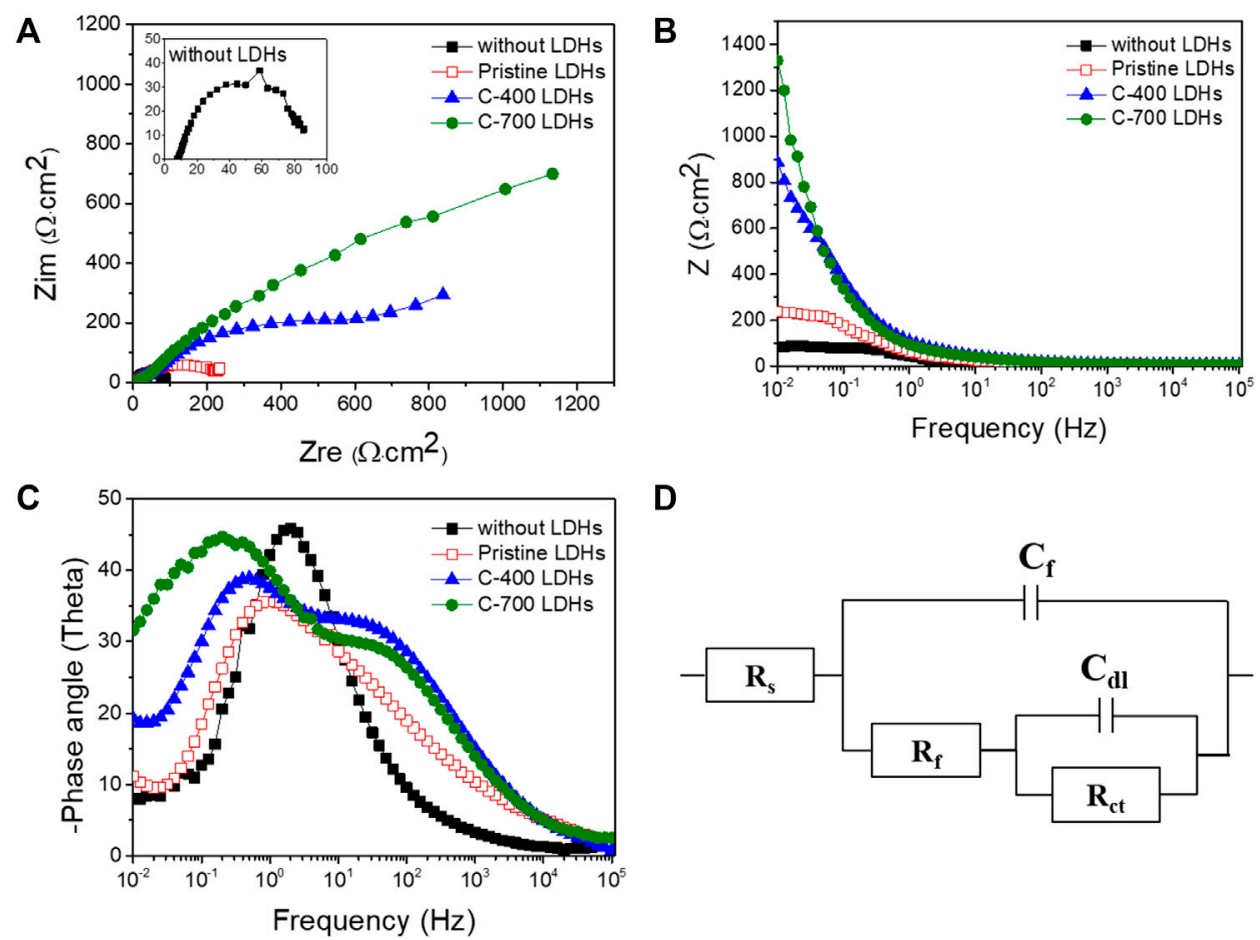

D

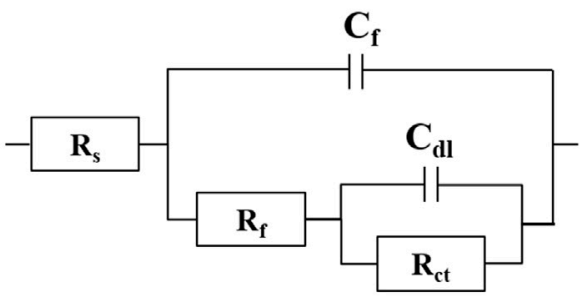

FIGURE 9 | (A) Nyquist plots, (B) Bode plots, and (C) phase angle plots collected at corrosion potentials in a $3.5 \mathrm{wt} \% \mathrm{NaCl}$ solution without LDHs or LDOs and with Pristine LDHs, C-400 LDOs, and C-700 LDOs. (D) Equivalent electrical circuit (EEC) used to fit the electrochemical impedance data.

TABLE 6 | Impedance parameters and calculated inhibition efficiencies (IE\%) in a $3.5 \mathrm{wt} \% \mathrm{NaCl}$ solution with and without LDHs or LDOs.

\begin{tabular}{|c|c|c|c|c|c|c|}
\hline Sample & $\begin{array}{c}\text { Parameter } R_{s} \\
\left(\Omega \cdot \mathrm{cm}^{2}\right)\end{array}$ & $C_{f}\left(\mu \mathrm{F} \cdot \mathrm{cm}^{-2}\right)$ & $R_{f}\left(\Omega \cdot \mathrm{cm}^{2}\right)$ & $C_{d l}\left(\mu \mathrm{F} \cdot \mathrm{cm}^{-2}\right)$ & $R_{c t}\left(\Omega \cdot \mathrm{cm}^{2}\right)$ & IE (\%) \\
\hline Without LDHs & 7.64 & $3.23 \times 10^{-3}$ & 9.92 & $8.04 \times 10^{-3}$ & 39.57 & - \\
\hline Pristine LDHs & 8.25 & $0.29 \times 10^{-3}$ & 22.11 & $3.26 \times 10^{-3}$ & 159.62 & 75.19 \\
\hline C-700 LDHs & 25.15 & $0.17 \times 10^{-3}$ & $3,519.89$ & $2.45 \times 10^{-3}$ & $3,520.01$ & 98.87 \\
\hline
\end{tabular}

corrosion of the steel specimen is significantly alleviated. Hence, the reduction in the $\mathrm{C}_{\mathrm{dl}}$ value is mainly attributed to a decrease in the exposed iron alloy surface area due to the presence of the LDHs. It is well known that the corrosion rate of steel is inversely proportional to the $\mathrm{R}_{\mathrm{ct}}$ value. In a solution without LDHs, the Rct value was $39.57 \Omega \mathrm{cm}^{2}$. However, the $R_{c t}$ value with pristine LDHs was $159.62 \Omega \mathrm{cm}^{2}$, and this parameter gradually increased to a maximum of $3,520.01 \Omega \mathrm{cm}^{2}$ for C-700 LDOs. To more clearly illustrate the corrosion mitigation effects of CaFe-LDHs and LDOs, the inhibition efficiency (IE\%) of the $\mathrm{CaFe}-\mathrm{LDH}$ and LDOs was calculated according to the following Equation 12:

$$
\operatorname{IE}(\%)=\frac{\mathrm{R}_{c t, \text { with } L D H}-\mathrm{R}_{c t, \text { without } L D H}}{\mathrm{R}_{c t, \text { with } L D H}}
$$

where $R_{c t}$, with LDHs and LDOs, and $R_{c t}$, without LDHs, represent the charge transfer resistances of the steel specimens in the presence and absence of $\mathrm{CaFe}-\mathrm{LDH}$ and $\mathrm{LDOs}$, respectively. From Table 6, it is evident that the solution containing both the iron alloy specimen and CaFe-LDHs and LDOs showed an inhibitory effect, whereas no effect was observed in the test solution without LDHs. In particular, the highest inhibition efficiency of 98.87\% was achieved with the C-700 LDOs.

\section{CONCLUSION}

Structure-modulated $\mathrm{CaFe}-\mathrm{LDHs}$ were fabricated at room temperature using a modified co-precipitation method. A high $\mathrm{Cl}^{-}$adsorption capability of $881.83 \mathrm{mg} / \mathrm{g}$ was achieved with $\mathrm{C}$ 700 LDOs (LDHs heat treated at $700^{\circ} \mathrm{C}$ ). The chloride removal capability exceeded three times the maximum performance in previous studies $(257 \mathrm{mg} / \mathrm{g})$ on chloride removal by LDHs. It was also confirmed that the kinetics were well fitted by a pseudo-second- 
order model, suggesting dominant chemical adsorption on CaFeLDHs and LDOs. The Langmuir isotherm models confirmed that the LDHs and LDOs effectively removed the target anions, primarily via monolayer sorption. Moreover, it was also confirmed that crystalline $\mathrm{CaO}$ was formed as a C-700 LDO moiety during the heat treatment of pristine $\mathrm{CaFe}-\mathrm{LDH}$, and this phase served as another source to enhance the $\mathrm{Cl}^{-}$removal by undergoing a chemical reaction. In particular, the highest inhibition efficiency of $98.87 \%$ was achieved with C-700 LDOs compared to iron alloys without LDHs. Based on the results obtained in this study, CaFe-LDOs demonstrate considerable potential for use as concrete fillers or additives in the construction industry to enhance the durability/sustainability of iron alloy reinforced buildings.

\section{DATA AVAILABILITY STATEMENT}

The original contributions presented in the study are included in the article/Supplementary Material, further inquiries can be directed to the corresponding author.

\section{AUTHOR CONTRIBUTIONS}

JP conceived of the experiments and prepared the manuscript. SY helped perform the analysis and discussed the results. $\mathrm{H}-\mathrm{BC}$ and

\section{REFERENCES}

Babou-Kammoe, R., Hamoudi, S., Larachi, F., and Belkacemi, K. (2012). Synthesis of CaCO3 Nanoparticles by Controlled Precipitation of Saturated Carbonate and Calcium Nitrate Aqueous Solutions. Can. J. Chem. Eng. 90, 26-33. doi:10. 1002/cjce. 20673

Bassuoni, M. T., and Nehdi, M. L. (2008). Durability of Self-Consolidating concrete to Different Exposure Regimes of Sodium Sulfate Attack. Mater. Struct. 42, 1039-1057. doi:10.1617/s11527-008-9442-2

Benício, L. P. F., Silva, R. A., Lopes, J. A., Eulálio, D., Santos, R. M. M. d., Aquino, L. A. d., et al. (2015). LAYERED DOUBLE HYDROXIDES: NANOMATERIALS FOR APPLICATIONS IN AGRICULTURE. Rev. Bras. Ciênc. Solo 39, 1-13. doi:10.1590/01000683rbcs2015081

Berrocal, C. G., Lundgren, K., and Löfgren, I. (2016). Corrosion of Steel Bars Embedded in Fibre Reinforced concrete under Chloride Attack: State of the Art. Cement Concrete Res. 80, 69-85. doi:10.1016/j.cemconres.2015.10.006

Butto, N., Cabrera-Barjas, G., and Neira-Carrillo, A. (2018). Electrocrystallization of CaCO3 Crystals Obtained through Phosphorylated Chitin. Crystals 8, 82. doi: $10.3390 /$ cryst8020082

Calisto, J. S., Pacheco, I. S., Freitas, L. L., Santana, L. K., Fagundes, W. S., Amaral, F. A., et al. (2019). Adsorption Kinetic and Thermodynamic Studies of the 2, 4 Dichlorophenoxyacetate $(2,4-\mathrm{D})$ by the $[\mathrm{Co}-\mathrm{Al}-\mathrm{Cl}]$ Layered Double Hydroxide. Heliyon 5, e02553. doi:10.1016/j.heliyon.2019.e02553

Chen, Y., Gao, J., Tang, L., and Li, X. (2016). Resistance of concrete against Combined Attack of Chloride and Sulfate under Drying-Wetting Cycles. Construction Building Mater. 106, 650-658. doi:10.1016/j.conbuildmat.2015. 12.151

Dorn, J. E. (1953). "Structure of Metals: Crystallographic Methods, Principles, and Data,". Editor S. B. Charles. 2nd (New York-London: McGraw-Hill), 117, 421-422. Science 1952. 661 pp. \$10.00. doi:10.1126/science.117.3042.421-a

Erickson, K. L., Bostrom, T. E., and Frost, R. L. (2005). A Study of Structural Memory Effects in Synthetic Hydrotalcites Using Environmental SEM. Mater. Lett. 59, 226-229. doi:10.1016/j.matlet.2004.08.035
H-SL contributed to editing. Y-HC contributed to the manuscript, accepted responsibility for the conducted research, and provided final approval. All authors have given approval to the final version of the manuscript.

\section{FUNDING}

This work was supported by a National Research Foundation of Korea (NRF) grant funded by the Korean government (MSIT) (No. 2015R1A5A1037548); the Industrial Strategic Technology Development Program (20010460, Developing the Ceramic ALD Precursors with High Corrosion Resistance and Core Parts of Deposition Etching Equipment for High Density Semiconductors) funded by the Ministry of Trade, Industry and Energy (MOTIE, Korea); and the Technology Innovation Program (20002694, Gas sensor) funded by the Ministry of Trade, Industry and Energy (MOTIE, Korea).

\section{SUPPLEMENTARY MATERIAL}

The Supplementary Material for this article can be found online at: https://www.frontiersin.org/articles/10.3389/fchem.2022.813008/ full\#supplementary-material

Evans, D. G., and Duan, X. (2006). Preparation of Layered Double Hydroxides and Their Applications as Additives in Polymers, as Precursors to Magnetic Materials and in Biology and Medicine. Chem. Commun. 37, 485-496. doi:10.1039/b510313b

Gupta, N. K., Saifuddin, M., Kim, S., and Kim, K. S. (2020). Microscopic, Spectroscopic, and Experimental Approach towards Understanding the Phosphate Adsorption onto Zn-Fe Layered Double Hydroxide. J. Mol. Liquids 297, 111935. doi:10.1016/j.molliq.2019.111935

Halajnia, A., Oustan, S., Najafi, N., Khataee, A. R., and Lakzian, A. (2013). Adsorption-desorption Characteristics of Nitrate, Phosphate and Sulfate on Mg-Al Layered Double Hydroxide. Appl. Clay Sci. 80-81, 305-312. doi:10.1016/ j.clay.2013.05.002

Hou, L., Li, Y., Sun, J., Zhang, S. H., Wei, H., and Wei, Y. (2019). Enhancement Corrosion Resistance of $\mathrm{Mg} \mathrm{Al}$ Layered Double Hydroxides Films by AnionExchange Mechanism on Magnesium Alloys. Appl. Surf. Sci. 487, 101-108. doi:10.1016/j.apsusc.2019.05.048

Imanieh, I., and Afshar, A. (2019). Corrosion protection of Aluminum by Smart Coatings Containing Layered Double Hydroxide (LDH) Nanocontainers. J. Mater. Res. Technology 8, 3004-3023. doi:10.1016/j.jmrt.2018.05.030

Ivánová, D., Albert, P., and Kavuličová, J. (2018). Nitrate Removal from Model Aqueous Solutions and Real Water by Calcined $\mathrm{Mg} / \mathrm{Al}$ Layered Double Hydroxides. Appl. Clay Sci. 152, 65-72. doi:10.1016/j.clay.2017.10.033

Ke, X., Bernal, S. A., and Provis, J. L. (2017). Uptake of Chloride and Carbonate by $\mathrm{Mg}-\mathrm{Al}$ and $\mathrm{Ca}-\mathrm{Al}$ Layered Double Hydroxides in Simulated Pore Solutions of Alkali-Activated Slag Cement. Cement Concrete Res. 100, 1-13. doi:10.1016/j. cemconres.2017.05.015

Kong, X., Ge, R., Liu, T., Xu, S., Hao, P., Zhao, X., et al. (2021). Super-stable Mineralization of Cadmium by Calcium-Aluminum Layered Double Hydroxide and its Large-Scale Application in Agriculture Soil Remediation. Chem. Eng. J. 407, 127178. doi:10.1016/j.cej.2020.127178

Liu, A., Ju, X., Tian, H., Yang, H., and Li, W. (2019). Direct Synthesis of Layered Double Hydroxides Monolayer Nanosheets for Co-assembly of Nanobrick wall Hybrid Film with Excellent Corrosion Resistance. Appl. Surf. Sci. 493, 239-249. doi:10.1016/j.apsusc.2019.06.295 
Lv, W., Yang, L., Fan, B., Zhao, Y., Chen, Y., Lu, N., et al. (2015). Silylated MgAl LDHs Intercalated with $\mathrm{MnO} 2$ Nanowires: Highly Efficient Catalysts for the Solvent-free Aerobic Oxidation of Ethylbenzene. Chem. Eng. J. 263, 309-316. doi:10.1016/j.cej.2014.11.009

Mahjoubi, F. Z., Khalidi, A., Abdennouri, M., and Barka, N. (2017). Zn-Al Layered Double Hydroxides Intercalated with Carbonate, Nitrate, Chloride and Sulphate Ions: Synthesis, Characterisation and Dye Removal Properties. J. Taibah Univ. Sci. 11, 90-100. doi:10.1016/j.jtusci.2015.10.007

Mishra, G., Dash, B., and Pandey, S. (2018). Layered Double Hydroxides: A Brief Review from Fundamentals to Application as Evolving Biomaterials. Appl. Clay Sci. 153, 172-186. doi:10.1016/j.clay.2017.12.021

Mu'azu, N. D., Jarrah, N., Kazeem, T. S., Zubair, M., and Al-Harthi, M. (2018). Bentonite-layered Double Hydroxide Composite for Enhanced Aqueous Adsorption of Eriochrome Black T. Appl. Clay Sci. 161, 23-34. doi:10.1016/ j.clay.2018.04.009

Muthulingam, S., and Rao, B. N. (2015). Non-uniform Corrosion States of Rebar in concrete under Chloride Environment. Corrosion Sci. 93, 267-282. doi:10.1016/ j.corsci.2015.01.031

Peng, C., Dai, J., Yu, J., and Yin, J. (2015). Calcined Mg-Fe Layered Double Hydroxide as an Absorber for the Removal of Methyl orange. AIP Adv. 5, 057138. doi:10.1063/1.4921455

Pradhan, B., and Bhattacharjee, B. (2011). Rebar Corrosion in Chloride Environment. Construction Building Mater. 25, 2565-2575. doi:10.1016/j. conbuildmat.2010.11.099

Rathee, G., Awasthi, A., Sood, D., Tomar, R., Tomar, V., and Chandra, R. (2019). A New Biocompatible Ternary Layered Double Hydroxide Adsorbent for Ultrafast Removal of Anionic Organic Dyes. Sci. Rep. 9, 16225. doi:10.1038/ s41598-019-52849-4

Romero Ortiz, G., Lartundo-Rojas, L., Samaniego-Benítez, J. E., Jiménez-Flores, Y., Calderón, H. A., and Mantilla, A. (2021). Photocatalytic Behavior for the Phenol Degradation of $\mathrm{ZnAl}$ Layered Double Hydroxide Functionalized with SDS. J. Environ. Manage. 277, 111399. doi:10.1016/j.jenvman.2020.111399

Santos, R. M. M. d., Gonçalves, R. G. L., Constantino, V. R. L., Santilli, C. V., Borges, P. D., Tronto, J., et al. (2017b). Adsorption of Acid Yellow 42 Dye on Calcined Layered Double Hydroxide: Effect of Time, Concentration, $\mathrm{pH}$ and Temperature. Appl. Clay Sci. 140, 132-139. doi:10.1016/j.clay.2017.02.005

Santos, R. M. M., Tronto, J., Briois, V., and Santilli, C. V. (2017a). Thermal Decomposition and Recovery Properties of $\mathrm{ZnAl}-\mathrm{CO} 3$ Layered Double Hydroxide for Anionic Dye Adsorption: Insight into the Aggregative Nucleation and Growth Mechanism of the LDH Memory Effect. J. Mater. Chem. A. 5, 9998-10009. doi:10.1039/c7ta00834a

Wu, Y., Yu, Y., Zhou, J. Z., Liu, J., Chi, Y., Xu, Z. P., et al. (2012). Effective Removal of Pyrophosphate by Ca-Fe-LDH and its Mechanism. Chem. Eng. J. 179, 72-79. doi:10.1016/j.cej.2011.10.053

Xu, J., Tan, Q., and Mei, Y. (2020). Corrosion protection of Steel by Mg-Al Layered Double Hydroxides in Simulated concrete Pore Solution: Effect of SO42-. Corrosion Sci. 163, 108223. doi:10.1016/j.corsci.2019.108223
Yamaguchi, N., Masuda, Y., Yamada, Y., Narusawa, H., Han-Cheol, C., Tamaki, Y., et al. (2015). Synthesis of $\mathrm{CaO}-\mathrm{SiO} 2$ Compounds Using Materials Extracted from Industrial Wastes. Ojinm 05, 1-10. doi:10. 4236/ojinm.2015.51001

Yan, Z., Zhu, B., Yu, J., and Xu, Z. (2016). Effect of Calcination on Adsorption Performance of Mg-Al Layered Double Hydroxide Prepared by a Water-In-Oil Microemulsion Method. RSC Adv. 6, 50128-50137. doi:10.1039/c6ra05253c

Yang, Z., Fischer, H., and Polder, R. (2013). Modified Hydrotalcites as a New Emerging Class of Smart Additive of Reinforced concrete for Anticorrosion Applications: A Literature Review. Mater. Corrosion 64, 1066-1074. doi:10. 1002/maco.201206915

Yoon, S., Moon, J., Bae, S., Duan, X., Giannelis, E. P., and Monteiro, P. M. (2014). Chloride Adsorption by Calcined Layered Double Hydroxides in Hardened Portland Cement Paste. Mater. Chem. Phys. 145, 376-386. doi:10.1016/j. matchemphys.2014.02.026

Zaghouane-Boudiaf, H., Boutahala, M., Tiar, C., Arab, L., and Garin, F. (2011). Treatment of 2,4,5-trichlorophenol by MgAl-SDBS Organo-Layered Double Hydroxides: Kinetic and Equilibrium Studies. Chem. Eng. J. 173, 36-41. doi:10. 1016/j.cej.2011.07.032

Zhou, J., Li, X., Li, W., Wei, F., Su, Y., Zhang, J., et al. (2015). Multi-step Removal Mechanism of Pyrophosphate Using CaFe-Layered Double Hydroxide at High pH. Appl. Clay Sci. 105-106, 21-26. doi:10.1016/j.clay.2014.12.001

Zuo, J., Wu, B., Luo, C., Dong, B., and Xing, F. (2019). Preparation of MgAl Layered Double Hydroxides Intercalated with Nitrite Ions and Corrosion protection of Steel Bars in Simulated Carbonated concrete Pore Solution. Corrosion Sci. 152, 120-129. doi:10.1016/j.corsci.2019.03.007

Conflict of Interest: Author SY was employed by the company Park Systems Corporation.

The remaining authors declare that the research was conducted in the absence of any commercial or financial relationships that could be construed as a potential conflict of interest.

Publisher's Note: All claims expressed in this article are solely those of the authors and do not necessarily represent those of their affiliated organizations, or those of the publisher, the editors and the reviewers. Any product that may be evaluated in this article, or claim that may be made by its manufacturer, is not guaranteed or endorsed by the publisher.

Copyright $\odot 2022$ Park, Yoo, Cho, Lee and Choa. This is an open-access article distributed under the terms of the Creative Commons Attribution License (CC BY). The use, distribution or reproduction in other forums is permitted, provided the original author(s) and the copyright owner(s) are credited and that the original publication in this journal is cited, in accordance with accepted academic practice. No use, distribution or reproduction is permitted which does not comply with these terms. 